\title{
Intervention Reporting of Published Trials Is Insufficient in Orthopaedic Surgery Journals: Application of the Template for Intervention Description and Replication Checklist
}

\author{
J. Michael Anderson, B.S., Aaron Stafford, B.S., Samuel Jellison, B.S., and \\ Matt Vassar, Ph.D.
}

Purpose: Outcomes of randomized controlled trials (RCTs) have been shown to influence clinical decision making. Thus, the quality and reliability of these outcomes are essential for both patients and medical care providers. To date, no study has assessed the quality of intervention reporting of RCTs in orthopaedics. The aim of this study was to evaluate the quality of intervention reporting of published RCTs in the field of orthopaedics using the Template for Intervention Description and Replication (TIDieR) checklist. Methods: In this cross-sectional analysis, we applied the TIDieR checklist to assess the quality of intervention reporting in orthopaedic RCTs. Additionally, we evaluated the TIDieR checklist's influence on intervention reporting by comparing overall adherence to checklist items in trials published before the TIDieR checklist's release versus trials published after its release. Finally, we assessed whether certain factors were associated with the quality of intervention reporting. Results: From a random sample of 300 publications in orthopaedic journals, 175 parallel-arm and cluster RCTs were identified. The overall rate of adherence to TIDieR items was $58.4 \%$. Only $31.4 \%$ of orthopaedic RCTs adhered to at least 6 of the 12 TIDieR checklist items, whereas $0 \%$ adhered to all 12 items. We found no significant improvement in the quality of intervention reporting in studies published after the TIDieR checklist's release compared with studies published before its release $(P=.97)$. Additionally, preregistered trials were associated with more complete intervention reporting. Conclusions: Our results suggest suboptimal reporting of orthopaedic RCT interventions. In addition, the TIDieR checklist's intended effect-to better the quality of RCT intervention reporting-appears to have fallen short of its goal. Clinical Relevance: Because outcomes of RCTs are used to guide clinical decision making, it is essential that orthopaedic surgeons and clinical practice guideline panels are equipped with high-quality published research. Increasing the accuracy of intervention reporting may lead to more accurate clinical application. Thus, adoption of more stringent reporting of trial interventions by researchers, authors, and journal editors may improve the quality of orthopaedic research, as well as improve patient outcomes.

$\mathbf{R}$ andomized controlled trials (RCTs) are critical to the advancement of evidence-based medicine and are essential resources for clinical decision making. In orthopaedic surgery, RCTs are considered Level I evidence by some orthopaedic surgery journals ${ }^{1}$ and are used by clinical practice guideline panels to establish

From Oklahoma State University Center for Health Sciences, Tulsa, Oklahoma, U.S.A. (J.M.A., S.J., M.V.); and Kansas City University of Medicine and Biosciences, Joplin, Missouri, U.S.A. (A.S.).

The authors report the following potential conflicts of interest or sources of funding: This study was funded through the 2019 Presidential Research Fellowship Mentor-Mentee Program at Oklahoma State University Center for Health Sciences. M.V. receives grant support from National Institute on Drug Abuse- National Institute on Alcohol Abuse and Alcoholism and U.S. Office of Research Integrity, Oklahoma Center for Advancement of Science and Technology and receives internal grants from Oklahoma State University Center for Health Sciences, outside the submitted work. Full ICMJE author robust practice recommendations. Considering the implications of trial findings in orthopaedics, the quality and completeness of reporting methodologic details in trial publications are imperative for readers to effectively evaluate research quality and interpret study outcomes. Accurate extrapolation of such outcomes is

disclosure forms are available for this article online, as supplementary material.

Received June 8, 2020; accepted September 21, 2020.

Address correspondence to J. Michael Anderson, B.S., Oklahoma State University Center for Health Sciences, 1111 W 17th St, Tulsa, OK 74137, U.S.A.E-mail: jande31@okstate.edu

(C) 2021 THE AUTHORS. Published by Elsevier Inc. on behalf of the Arthroscopy Association of North America. This is an open access article under the CC BY-NC-ND license (http://creativecommons.org/licenses/by-nc-nd/4.0/). 2666-061X/20944

https://doi.org/10.1016/j.asmr.2020.09.019 
crucial to make informed judgments when applying these outcomes in the clinical setting. Despite the utility of orthopaedic trials, significant gaps remain in their reporting, which is problematic for both readers and researchers. $^{2-5}$

Previous studies using the Consolidated Standards of Reporting Trials (CONSORT) statement-a 25-item checklist outlining a set of recommendations to increase the transparency of RCT reporting ${ }^{6}$ - have indicated that methodologic reporting of orthopaedic trials needs improvement. ${ }^{3,4}$ For example, Chess and Gagnier ${ }^{7}$ noted inadequate reporting in $42 \%$ of orthopaedic RCTs. Chen et al. ${ }^{2}$ found that $66 \%$ of trials did not sufficiently report blinding and nearly $60 \%$ failed to report allocation concealment. Montané et al. ${ }^{4}$ reported that $75 \%$ of RCTs scored 12 or less overall on CONSORT checklist items, $56.5 \%$ failed to report the estimated effect size, and $25 \%$ did not report the interpretation of potential bias or lack of precision of results. These findings suggest that key methodologic components, as detailed in the CONSORT Statement, are consistently under-reported in orthopaedic RCTs.

The CONSORT Statement has achieved much in elucidating areas in need of improvement. However, this checklist includes only a single item dedicated to intervention reporting. Complete intervention reporting is necessary for the reproducibility of interventions in future studies or the application of trial interventions to patient care. To combat this problem, the Template for Intervention Description and Replication (TIDieR) was created to better explain the "who, what, when, where, and why" regarding trial interventions. ${ }^{8}$ Although the overall completeness of trial reporting using the CONSORT guidelines has been extensively evaluated, little is known about the quality of intervention reporting in particular. Thus, we evaluated the quality of intervention reporting in orthopaedic trials and assessed whether the publication of the TIDieR checklist has influenced intervention reporting.

\section{Methods}

This cross-sectional analysis did not involve human subjects and, thus, was not subject to institutional review board oversight. Our study is reported using a modified version of the Preferred Reporting Items for Systematic Reviews and Meta-analyses (PRISMA) guidelines. ${ }^{9}$ All versions of the study protocol, analysis scripts, materials, and data are available on the Open Science Framework (Center for Open Science) to foster study reproducibility and transparency. ${ }^{10}$

\section{Search}

Two authors (S.J. and M.V.) searched PubMed (including the MEDLINE collection) for RCTs published in orthopaedic surgery journals. To perform this search, we used PubMed's clinical trial filter (Clinical Trial [ptyp]) and restricted returns by publication date. The following journals were included: The American Journal of Sports Medicine; The Journal of Bone and Joint Surgery; Clinical Orthopaedics and Related Research; Spine; Knee Surgery, Sports Traumatology, Arthroscopy; The Journal of Arthroplasty; Arthroscopy: The Journal of Arthroscopic $\theta$ Related Surgery; The Spine Journal; European Spine Journal; and The Bone $\theta$ Joint Journal. The selection of these journals was based on the 2019 Google Scholar h5index "Orthopedic Medicine and Surgery" subcategory, which ranked these journals as the top 10 journals in orthopaedic surgery. S.J. and M.V. searched these journals in PubMed to identify all RCTs published from January 1, 2011, to December 31, 2013, and from January 1, 2016, to December 31, 2018. Our aim was to select cohorts of studies published before and after the March 2014 publication of the TIDieR checklist and assess its influence, if any, on RCT intervention reporting. The period between TIDieR publication and the start date of the second search permitted 22 months for the TIDieR checklist to take effect. We randomly sampled 150 records from each search (300 total) using Microsoft Excel's random number function.

\section{Eligibility}

The following types of RCTs were included: parallelarm, crossover, and cluster trials. Exclusions are listed in Figure 1.

\section{Primary and Secondary Outcomes}

Our primary outcome was the percentage of completion of the TIDieR checklist. ${ }^{8}$ Our secondary outcomes were (1) to compare the completeness of intervention reporting before and after the publication of the TIDieR checklist and (2) to evaluate factors associated with intervention reporting.

\section{Training}

Prior to data extraction, S.J. and M.V. developed a standardized training module. Two investigators (M.A. and A.S.) completed the training module prior to study commencement. Training was led by S.J. and comprised the following: (1) an overview of the study, (2) a review of the article by Hoffmann et al. ${ }^{8}$ and a brief review of all 12 TIDieR checklist items, and (3) data extraction for 3 example RCTs. This module was recorded and is available online for reference. ${ }^{10}$

\section{Screening}

Rayyan (Qatar Computing Research Institute), a systematic review application, was used to screen PubMed records for eligibility. J.M.A. and A.S. screened all records in a double, masked fashion. After screening, these investigators held a consensus meeting to resolve any disagreements. S.J. and M.V. were available for third-party adjudication. 


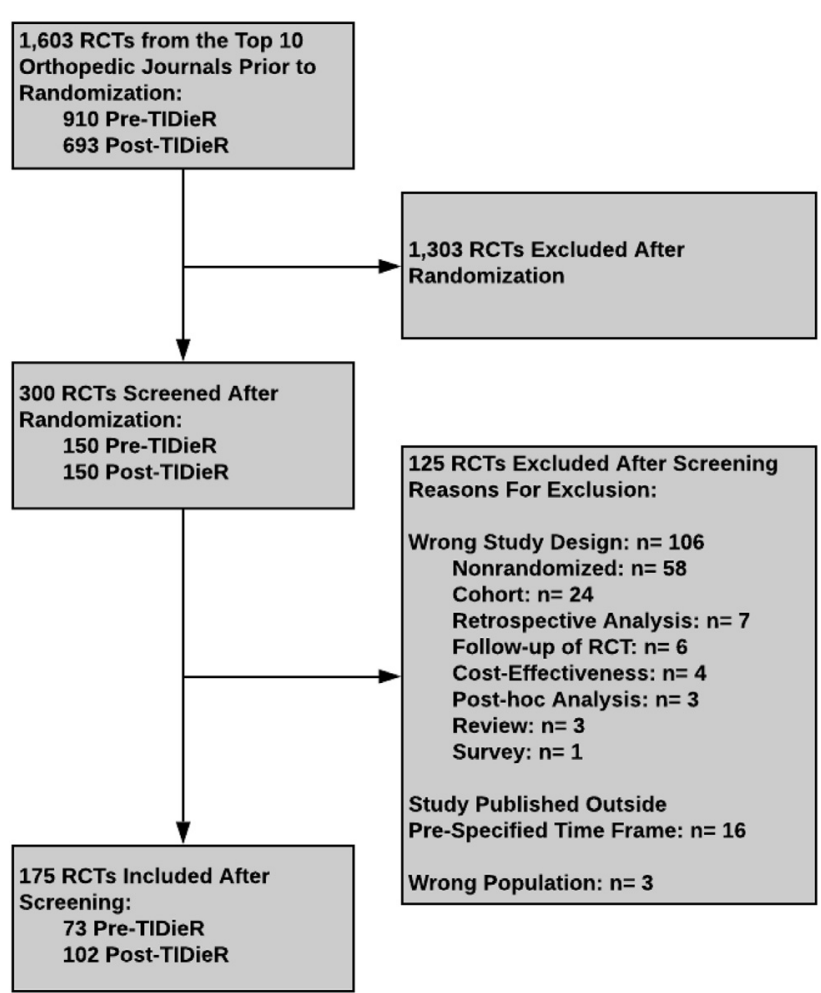

Fig 1. Flowchart of included and excluded randomized controlled trials (RCTs). (TIDieR, Template for Intervention Description and Replication.)

\section{Data Extraction}

Data extraction was performed by J.M.A. and A.S. As before, each investigator was masked to the other investigator's responses. After data extraction and scoring, both investigators held a final consensus meeting to resolve discrepancies. S.J. and M.V. were available for third-party adjudication. The investigators used a Google Form developed by S.J. that contained all 12 checklist items, as outlined by Hoffmann et al., ${ }^{8}$ as well as other variables that previous studies found to be related to completeness of reporting when using the CONSORT guidelines. ${ }^{11-16}$ This form is available online for reference. ${ }^{10}$

\section{Data Analysis}

For our primary objective, we evaluated the completeness of intervention reporting of RCTs in orthopaedic surgery. For each trial, the overall completeness of reporting (i.e., number of TIDieR checklist items reported) was measured and assigned a point value: 1 point for complete compliance with an item, 0.5 points for partial compliance, and 0 points for items not reported. To summarize adherence to individual checklist items, we used frequencies, percentages, and $95 \%$ confidence intervals. We also summarized data by item to evaluate which items were sufficiently reported and which were under-reported. We characterized the distribution of trials by the number of reported TIDieR items using a histogram. For this graph, we considered an item to be reported only if it was completely reported by the authors; partially completed items were considered not reported.

We conducted an interrupted time-series analysis to investigate whether publication of the TIDieR checklist improved intervention reporting in orthopaedic RCTs. To perform this analysis, TIDieR checklist completion was scored as a percentage of completion at the trial level. Interrupted time-series analysis has been used in previous studies to evaluate the effect of reporting guidelines on the completeness of reporting. ${ }^{17}$ Because this analysis requires only 1 data point per period, we calculated the mean adherence for all trials published in the same month and year. Standard errors were estimated using the Newey-West method. ${ }^{18}$ We used Stata's "itsa" command (StataCorp).

We used generalized estimating equations (GEEs) to evaluate whether particular trial characteristics (or demographic characteristics) were associated with intervention reporting in orthopaedic RCTs. ${ }^{19}$ We chose GEEs because we expected clustering in our data, such that trials published within the same journal would likely adhere to the same reporting guidance. We specified a Poisson distribution (because our outcome variable was count data), a log link function, and an exchangeable correlation structure. Our resulting coefficients were exponentiated and presented as incidence rate ratios with $95 \%$ confidence intervals and $P$ values. Because of disproportionate sample sizes, we made the post hoc decision to cluster some descriptive trial characteristics into categories, where applicable. Stata's "xtgee" command was used for the analysis. For all analyses, the type I error $(\alpha)$ was set at .05 a priori. We used MATLAB (The MathWorks) ${ }^{20}$ to prepare data for the final analysis and Stata (version 15.1) for all analyses.

\section{Results}

Our search returned 1,603 publications, from which a random sample of 300 publications was generated and further analyzed. Of these, 175 randomly sampled publications were included whereas 125 were excluded (Fig 1).

\section{Sample Characteristics}

Our final sample included 175 RCTs, with the largest percentages being published in The Journal of Arthroplasty $(\mathrm{n}=40)$ and Knee Surgery, Sports Traumatology, Arthroscopy $(\mathrm{n}=32)$. Of the journals included in our final sample, 7 of $9(77.8 \%)$ either require or recommend adherence to the CONSORT guidelines in the "instructions for authors" sections on their websites whereas 0 of 9 explicitly endorse or require adherence to the TIDieR checklist (Table 1). Only 48 publications explicitly mentioned following the CONSORT 
Table 1. Summary of Journal Endorsement of CONSORT and/or TIDieR Guidelines for RCT Intervention Reporting

\begin{tabular}{lll}
\hline \multicolumn{1}{c}{ Journal Name } & $\begin{array}{c}\text { Endorsement } \\
\text { of CONSORT }\end{array}$ & $\begin{array}{c}\text { Endorsement } \\
\text { of TIDieR }\end{array}$ \\
\hline $\begin{array}{l}\text { The Journal of Arthroplasty } \\
\text { Knee Surgery, Sports }\end{array}$ & Yes & No \\
$\begin{array}{l}\text { Traumatology, Arthroscopy } \\
\text { Spine }\end{array}$ & No & No \\
$\begin{array}{l}\text { The American Journal of Sports } \\
\text { Medicine }\end{array}$ & Yes & No \\
$\begin{array}{l}\text { Clinical Orthopaedics and Related } \\
\text { Research }\end{array}$ & Yes & No \\
$\begin{array}{l}\text { European Spine Journal } \\
\text { Arthroscopy: The Journal of }\end{array}$ & Yes & No \\
$\begin{array}{l}\text { Arthroscopic } \theta \text { Related Surgery } \\
\text { The Bone } \theta \text { Joint Journal }\end{array}$ & No & No \\
$\begin{array}{l}\text { The Spine Journal } \\
\text { The Journal of Bone } \theta \text { Joint }\end{array}$ & Yes & Nos \\
Surgery & & No \\
\hline $\begin{array}{l}\text { CONSORT, Consolidated Standards of Reporting Trials; RCT, ran- } \\
\text { domized controlled trial; TIDieR, Template for Intervention Descrip- } \\
\text { tion and Replication. }\end{array}$ &
\end{tabular}

guidelines, whereas no trial mentioned adhering to the TIDieR checklist. Table 2 provides further sample characteristics.

\section{Adherence to TIDieR Checklist Items}

The mean number of TIDieR items reported was 7.0 (standard deviation, 1.48) out of a possible 12. Six items or fewer were reported in $31.4 \%$ of RCTs (55 of 175). Furthermore, no trial adhered to all 12 TIDieR checklist items. All 175 trials included a name or phrase describing the intervention, as well as the rationale, theory, or goal of the intervention. Other items with greater than $75 \%$ adherence included items 4 ("What procedures?"), 6 ("How?"), and 8 ("When and how much?"). Items with poor adherence $(<20 \%)$ included items 9 ("Tailoring?"), 10 ("Modifications?"), 11 ("How well: planned?"), and 12 (“How well: actual?").

\section{Secondary Analysis}

As a secondary outcome, our study analyzed whether publication of the TIDieR checklist affected intervention reporting. Figure 2 displays the mean percentage of completion by month for trials published before and after the TIDieR checklist's publication. The results suggest that the publication of the TIDieR checklist did not result in a statistically significant trend in the percentage of completion of the TIDieR checklist items $(P=.97)$. Table 3 shows the overall percentage of adherence to each TIDieR item for the 2 groups of orthopaedic trials, those published prior to and after the TIDieR checklist's release.

Additionally, we sought to determine whether specific characteristics influenced the likelihood that an RCT intervention was more completely reported. The
Table 2. Baseline Characteristics of Sampled RCTs from Top Orthopaedic Surgery Journals

\begin{tabular}{|c|c|c|}
\hline Characteristic & Google-Form Response & $\mathrm{n}(\%)$ \\
\hline \multirow[t]{9}{*}{ Name of journal } & The Journal of Arthroplasty & $40(22.9)$ \\
\hline & $\begin{array}{l}\text { Knee Surgery, Sports } \\
\text { Traumatology, Arthroscopy }\end{array}$ & $32(18.3)$ \\
\hline & Spine & $21(12)$ \\
\hline & $\begin{array}{l}\text { The American Journal of Sports } \\
\text { Medicine }\end{array}$ & $20(11.4)$ \\
\hline & $\begin{array}{l}\text { Clinical Orthopaedics and Related } \\
\text { Research }\end{array}$ & $15(8.6)$ \\
\hline & European Spine Journal & $14(8.0)$ \\
\hline & $\begin{array}{l}\text { Arthroscopy: The Journal of } \\
\text { Arthroscopic } \theta \text { Related Surgery }\end{array}$ & $14(8.0)$ \\
\hline & The Bone $\theta$ Joint Journal & $12(6.8)$ \\
\hline & The Spine Journal & $7(4.0)$ \\
\hline \multirow[t]{7}{*}{ Source of funding } & Not mentioned & $64(36.6)$ \\
\hline & Industry & $36(20.6)$ \\
\hline & None & $30(17.1)$ \\
\hline & Public & $20(11.4)$ \\
\hline & Mixed & $11(6.3)$ \\
\hline & Private & $9(5.1)$ \\
\hline & Hospital & $5(2.9)$ \\
\hline \multirow[t]{6}{*}{ Hypothesis } & Superiority & $91(47.9)$ \\
\hline & Not sure & $64(33.7)$ \\
\hline & Equivalence & $21(11.1)$ \\
\hline & Other & $8(4.2)$ \\
\hline & Noninferiority & $4(2.1)$ \\
\hline & $\begin{array}{l}\text { Mixed (superiority and } \\
\text { equivalence) }\end{array}$ & $2(1.1)$ \\
\hline \multirow[t]{2}{*}{ Study design } & Parallel arm & $172(98.3)$ \\
\hline & Cluster & $3(1.7)$ \\
\hline \multirow[t]{5}{*}{ Intervention } & Procedure & $69(39.4)$ \\
\hline & Drug & $39(22.3)$ \\
\hline & Other & $36(20.6)$ \\
\hline & Device & $25(14.3)$ \\
\hline & Mixed & $6(3.4)$ \\
\hline \multirow[t]{3}{*}{ Blinding } & No blinding & $76(43.4)$ \\
\hline & Single blind & $39(22.3)$ \\
\hline & Double blind & $60(34.3)$ \\
\hline \multirow{4}{*}{$\begin{array}{l}\text { No. of participants per } \\
\text { trial }\end{array}$} & $<60$ & $63(36.0)$ \\
\hline & $60-170$ & $88(50.3)$ \\
\hline & $171-280$ & $15(8.6)$ \\
\hline & $>280$ & $9(5.1)$ \\
\hline \multirow{4}{*}{$\begin{array}{l}\text { Country where trial } \\
\text { was conducted }\end{array}$} & Outside of United States & $133(76)$ \\
\hline & United States & $40(22.8)$ \\
\hline & Both & $1(0.6)$ \\
\hline & Not mentioned & $1(0.6)$ \\
\hline \multirow{2}{*}{ Conducting center } & Single center & $148(84.6)$ \\
\hline & Multicenter & $27(15.4)$ \\
\hline \multirow{2}{*}{$\begin{array}{l}\text { RCTs with CONSORT } \\
\text { endorsement }\end{array}$} & Yes & $48(27.4)$ \\
\hline & No & $127(72.6)$ \\
\hline \multirow{2}{*}{$\begin{array}{l}\text { RCTs with TIDieR } \\
\text { endorsement }\end{array}$} & Yes & $0(0)$ \\
\hline & No & $175(100)$ \\
\hline \multirow{2}{*}{$\begin{array}{l}\text { Trial prospectively } \\
\text { registered }\end{array}$} & Yes & $63(36)$ \\
\hline & No & $112(64)$ \\
\hline
\end{tabular}

NOTE. A total of 175 RCTs were included in the analysis.

CONSORT, Consolidated Standards of Reporting Trials; RCT, randomized controlled trial; TIDieR, Template for Intervention Description and Replication.

results from our GEE model suggest that preregistered trials were associated with better TIDieR adherence than trials that were not preregistered. In addition, 


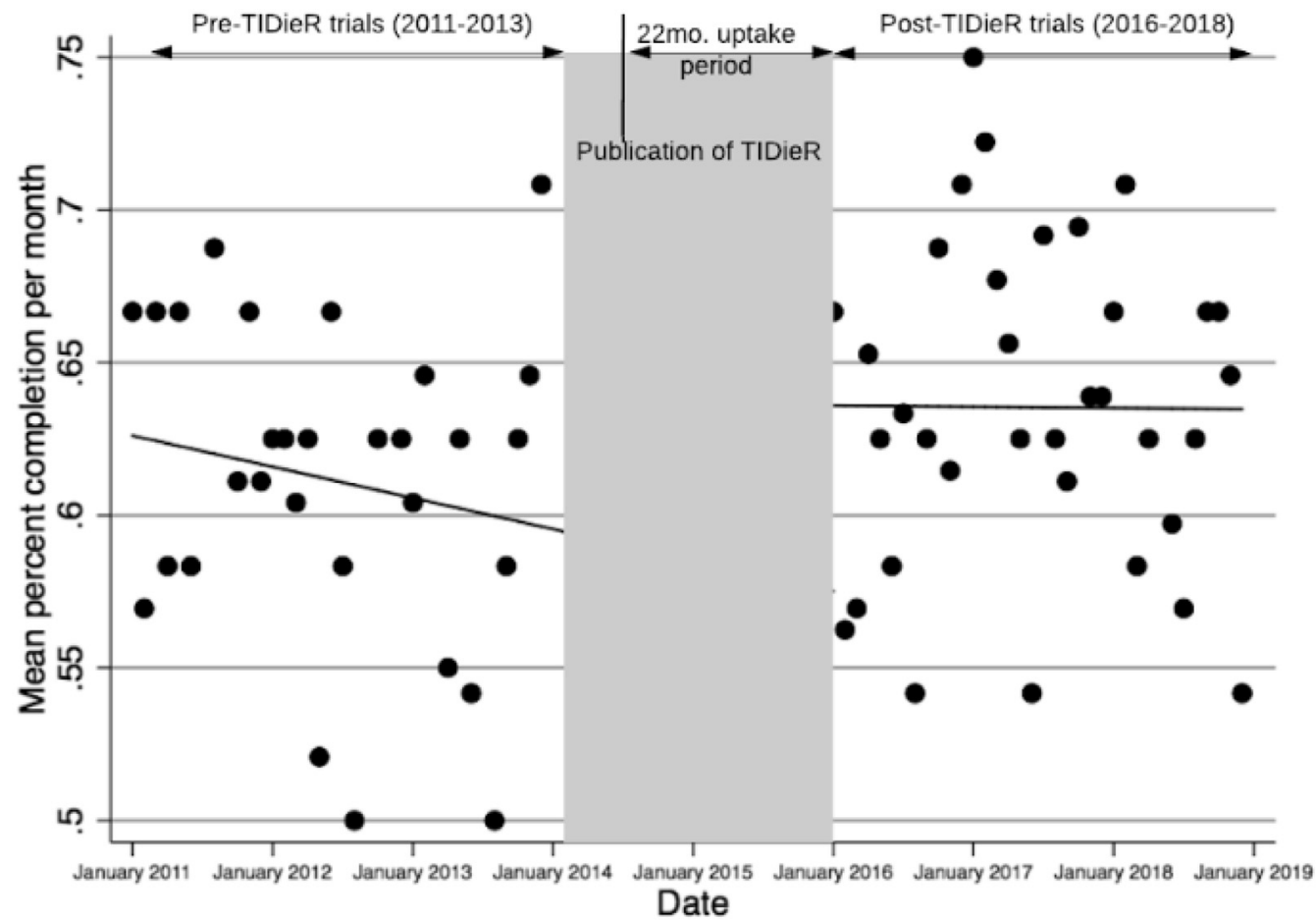

Fig 2. Interrupted time-series analysis of mean percentage of adherence to Template for Intervention Description and Replication (TIDieR) items.

multicenter trials and trials conducted within the United States were associated with poorer TIDieR adherence (Table 4).

\section{Discussion}

Our analysis of 175 RCTs in orthopaedics showed suboptimal intervention reporting of TIDieR checklist items. We found that only $58.4 \%$ of TIDieR items were adequately reported, which indicates that there is room for improvement of intervention reporting in orthopaedic trials. Commonly omitted checklist items included intervention modifications, whether the intervention was personalized or tailored, and assessment of intervention fidelity. Our results are similar to those of previous studies in other fields of medicine. $^{21-24}$ For example, a 2019 systematic review of 98

Table 3. Percentage of Adherence to TIDieR Checklist Items by Prespecified Period and Overall

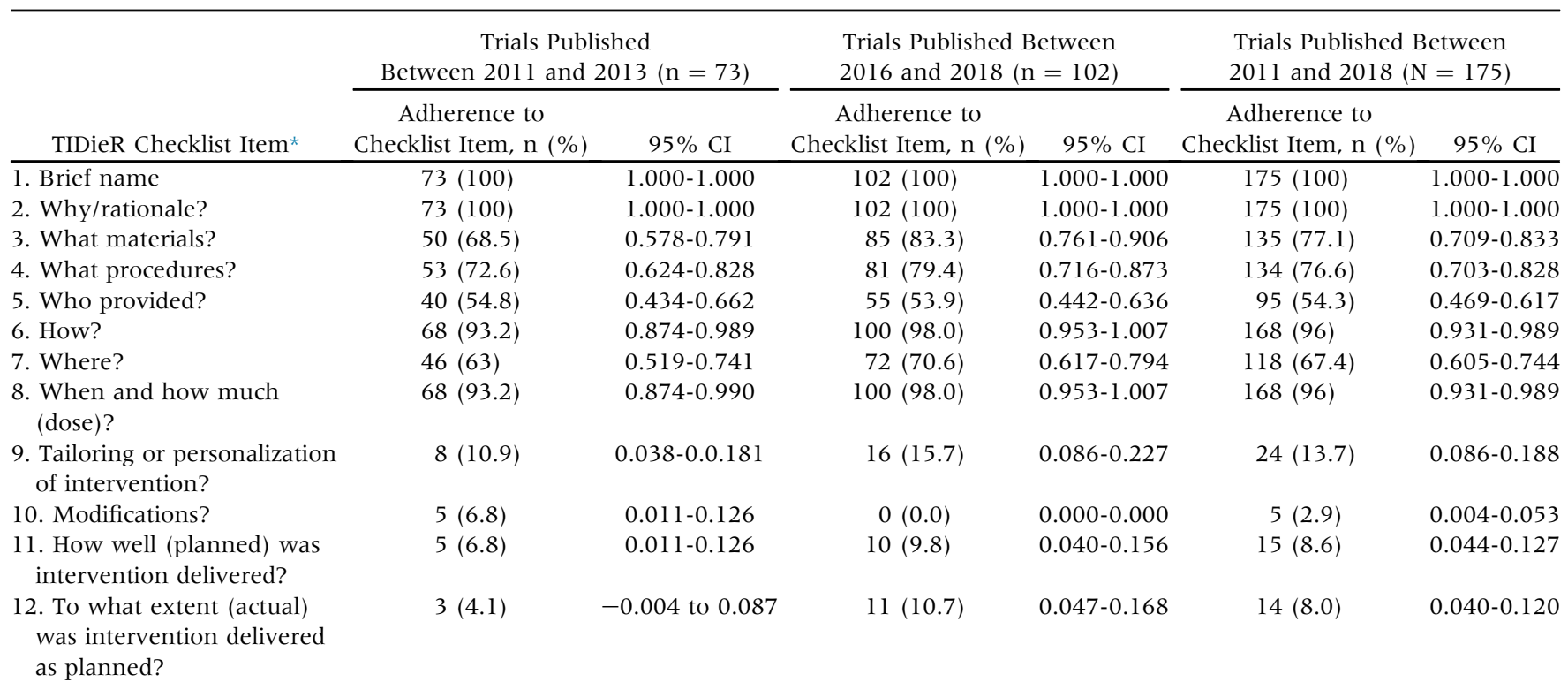

CI, confidence interval; TIDieR, Template for Intervention Description and Replication.

*Items were included in the calculation of the percentage of adherence if "completely" compliant with the TIDieR item. 
Table 4. Characteristics Associated With Intervention Reporting

\begin{tabular}{|c|c|c|c|}
\hline \multirow[b]{2}{*}{ Characteristic } & \multicolumn{3}{|c|}{ Variable } \\
\hline & IRR & $P$ Value & $95 \% \mathrm{CI}$ \\
\hline \multicolumn{4}{|l|}{ No. of authors } \\
\hline$<4$ & 1 & Reference & Reference \\
\hline $4-7$ & 0.97 & 0.313 & $0.92-1.03$ \\
\hline$>7$ & 1.99 & 0.971 & $0.92-1.09$ \\
\hline \multicolumn{4}{|l|}{ Funding source } \\
\hline Industry and private & 1 & Reference & Reference \\
\hline $\begin{array}{l}\text { Public and mixed } \\
\text { funding sources }\end{array}$ & 1.05 & 0.059 & $1.00-1.10$ \\
\hline Not mentioned & 1.02 & 0.565 & $0.95-1.10$ \\
\hline None & 0.99 & 0.688 & $0.92-1.05$ \\
\hline \multicolumn{4}{|l|}{ Hypothesis } \\
\hline Superiority & 1 & Reference & Reference \\
\hline All other hypotheses & 0.97 & 0.267 & $0.92-1.02$ \\
\hline \multicolumn{4}{|l|}{ Study design } \\
\hline Parallel arm & 1 & Reference & Reference \\
\hline Crossover & 0.99 & 0.811 & $0.88-1.10$ \\
\hline \multicolumn{4}{|l|}{ Intervention type } \\
\hline Procedure & 1 & Reference & Reference \\
\hline Drug & 1.02 & 0.471 & 0.96-1.09 \\
\hline $\begin{array}{l}\text { Non-procedure and } \\
\text { non-drug }\end{array}$ & 1.05 & 0.084 & $0.99-1.10$ \\
\hline \multicolumn{4}{|l|}{ Blinding } \\
\hline No blinding & 1 & Reference & Reference \\
\hline $\begin{array}{l}\text { Blinding (single or } \\
\text { double) }\end{array}$ & 0.99 & 0.489 & $0.96-1.02$ \\
\hline \multicolumn{4}{|l|}{ No. of participants } \\
\hline$<60^{\circ}$ & 1 & Reference & Reference \\
\hline $60-170$ & 0.96 & 0.069 & $0.92-1.00$ \\
\hline $171-280$ & 0.97 & 0.669 & $0.84-1.12$ \\
\hline$>280$ & 1.00 & 0.984 & $0.86-1.16$ \\
\hline \multicolumn{4}{|l|}{ Location of trial } \\
\hline $\begin{array}{l}\text { Outside of United } \\
\text { States, multiple } \\
\text { locations including } \\
\text { United States, or } \\
\text { not mentioned }\end{array}$ & 1 & Reference & Reference \\
\hline United States & 0.95 & 0.011 & $0.92-0.99$ \\
\hline \multicolumn{4}{|l|}{ Conducting center } \\
\hline Single center & 1 & Reference & Reference \\
\hline Multicenter & 0.92 & $<0.001$ & $0.89-0.95$ \\
\hline \multicolumn{4}{|l|}{$\begin{array}{l}\text { CONSORT } \\
\text { endorsement by trial } \\
\text { authors }\end{array}$} \\
\hline No & 1 & Reference & Reference \\
\hline Yes & 0.99 & 0.806 & $0.92-1.06$ \\
\hline \multicolumn{4}{|l|}{$\begin{array}{l}\text { TIDieR endorsement by } \\
\text { trial authors }\end{array}$} \\
\hline No & 1 & Reference & Reference \\
\hline Yes & - & - & - \\
\hline \multicolumn{4}{|l|}{ Trial registry } \\
\hline None & 1 & Reference & Reference \\
\hline Yes, listed & 1.06 & 0.009 & $1.01-1.10$ \\
\hline \multicolumn{4}{|l|}{$\begin{array}{l}\text { No. of sources in which } \\
\text { information was } \\
\text { found }\end{array}$} \\
\hline 1 & 1 & Reference & Reference \\
\hline$\geq 2$ & 1.02 & 0.304 & $0.98-1.06$ \\
\hline
\end{tabular}

CI, confidence interval; CONSORT, Consolidated Standards of Reporting Trials; IRR, incidence rate ratio; TIDieR, Template for Intervention Description and Replication.
RCTs reporting 134 interventions for major depressive disorder found that only $55.2 \%$ of "core items" were completely reported. ${ }^{25}$ Moreover, a study assessing intervention reporting of 200 physiotherapy RCTs found that nearly $25 \%$ of trials did not adequately describe at least 6 TIDieR items for the intervention groups. ${ }^{26}$ Furthermore, we found no significant improvement in the percentage of adherence to TIDieR checklist items in studies published after the checklist's release compared with studies published prior to its release. These findings suggest inadequate completeness of intervention reporting in orthopaedic trials, even after the publication of the TIDieR checklist. Taken together, the findings of our study and previous studies shed light on significant gaps in intervention reporting across multiple areas of medicine. Because the feasibility of reproducing a study largely depends on intervention reporting, we address areas of weakness of TIDieR adherence specific to orthopaedic RCTs that, if corrected, can promote an environment that facilitates reproducible research.

Our study found consistent gaps in intervention reporting in orthopaedic trials that may limit reproducibility and have downstream effects on patient care. ${ }^{21,27,28}$ Two particular TIDieR items were most often omitted, intervention fidelity and intervention modifications. First, intervention fidelity-the continual appraisal and enhancement of reliability and internal validity of an experiment ${ }^{29}$-assesses the extent to which an intervention was delivered as intended. ${ }^{30}$ Omitting this information can have widespread negative consequences throughout biomedical research and clinical practice. For example, when fidelity is not evaluated, outcomes may be due to either an effective treatment or an unknown factor added to the intervention or overlooked during its delivery. ${ }^{31} \mathrm{~A}$ resultant type I error (the belief that a nonsignificant outcome is significant) or type II error (the belief that a significant outcome is nonsignificant) may influence future research and patient care. Second, modifications made to the intervention should be clearly documented such that results can be accurately interpreted and reproduced. For example, Koh et al. ${ }^{32}$ studied the effect of single-row versus double-row suture anchor repair in rotator cuff tears. However, after the study began, the investigators switched from metal to bioabsorbable sutures. Without this information, future attempts to replicate this study could produce conflicting results that are difficult to explain. Omitting these essential intervention details is concerning for researchers and clinicians because it prohibits early detection of protocol deviations and ultimately may result in unforeseen costs and the waste of research resources. ${ }^{31}$ Thus, we assert that authors should consider implementing strategies to assess intervention fidelity to increase the 
transparency, reliability, and validity of study designs and outcomes.

Since the TIDieR checklist's publication in 2014, intervention reporting in orthopaedic trials has not experienced significant improvement. Our time-series analysis showed a slight yet nonsignificant increase in adherence to TIDieR items in trials published after the TIDieR checklist's release. These findings suggest that the TIDieR checklist has fallen short of its desired effect. Previous studies have offered several explanations for why reporting guidelines are not used appropriately. For example, Hirst and Altman ${ }^{33}$ have suggested that reporting guidelines are not used appropriately because authors lack awareness of the newest guidelines and may not understand their usefulness. As an attainable solution to this problem, we recommend the incorporation of the TIDieR checklist directly into the more well-known, -used, and -cited CONSORT checklist for RCT reporting. ${ }^{34}$ This integration would be seemingly effortless because the TIDieR checklist is a direct extension of item 5 of the CONSORT guidelines, which only addresses the how and when regarding trial intervention. In our sample, items 6 ("How?") and 8 ("When?") of the TIDieR checklist were adequately reported in $96 \%$ of orthopaedic RCTs (168 of 175). These findings indicate that authors provided sufficient detail to comply with item 5 of the widely used CONSORT guidelines but failed to report the necessary level of detail needed to fulfill all aspects of the TIDieR checklist. Considering that 7 of the 9 journals from which our sample of orthopaedic RCTs was collected currently endorse or require author adherence to the CONSORT guidelines, we contend that merging the TIDieR checklist with the CONSORT guidelines might increase authors' awareness-and subsequent implementation - of the TIDieR checklist in orthopaedic RCTs.

If integrating the TIDieR checklist into the current CONSORT guidelines is not plausible, we recommend that journals at least consider endorsing the TIDieR checklist alongside other reporting guidelines. Previous studies have shown the influence of journal endorsement on the quality of RCT reporting. For example, a 2012 systematic review of 53 meta-analyses reporting results from over 16,000 RCTs found increased RCT reporting quality for trials published in journals endorsing the CONSORT guidelines compared with non-endorsing journals. ${ }^{35}$ Currently, some journals require that authors adhere to both the CONSORT and TIDieR guidelines when submitting the results of an RCT for review. For instance, the Journal of Orthopaedic $\theta$ Sports Physical Therapy currently requires authors to submit a completed CONSORT and TIDieR checklist at the time of submission; otherwise, the manuscript "will be returned to the authors." ${ }^{36}$ Enforcing similar requirements by journals in orthopaedic surgery might be the first step in increasing the quality of orthopaedic RCT intervention reporting.

Several influential parties in the medical community have promoted the use of reporting guidelines to increase the transparency and reliability of study outcomes. For instance, the International Committee of Medical Journal Editors ${ }^{37}$ and the National Library of Medicine ${ }^{38}$ both encourage journals to promote and monitor reporting standards of submitted manuscripts. In rehabilitation medicine, an editorial published by 28 journal editors has emphasized their journals' decisions to adopt a more aggressive stance on reporting guidelines. ${ }^{39}$ A similar alliance in the orthopaedic literature might help raise awareness and increase the standards for adequate intervention reporting. Ultimately, questions remain about educating researchers on how to use and adopt reporting guidelines. Some investigators offered the use of software programs to facilitate more complete RCT reporting. One such program uses an online writing tool that applies the CONSORT Statement during the initial drafting of the trial. ${ }^{40}$ This program outlines all essential CONSORT items in a bulleted fashion, followed by examples of proper reporting practices. The use of this software has been associated with more complete reporting of CONSORT items ${ }^{40}$; thus, a similar Web-based program using the TIDieR checklist might be worth exploring.

\section{Limitations}

Regarding limitations, we used a random sample of RCTs from the published orthopaedic literature; therefore, our results may not be generalizable across the breadth of the entire field. In addition, we evaluated only orthopaedic RCTs. The same study performed in a different area of medicine might yield different outcomes. Finally, with the TIDieR checklist's recent publication in 2014, it is possible that a similar study conducted at a later date might yield differing outcomes.

\section{Conclusions}

Our results suggest suboptimal reporting of orthopaedic RCT interventions. In addition, the TIDieR checklist's intended effect-to better the quality of RCT intervention reporting-appears to have fallen short of its goal.

\section{References}

1. Wright JG, Swiontkowski MF, Heckman JD. Introducing levels of evidence to the journal. J Bone Joint Surg Am 2003;85:1-3.

2. Chen X, Zhai X, Wang X, Su J, Li M. Methodological reporting quality of randomized controlled trials in three spine journals from 2010 to 2012. Eur Spine J 2014;23: 1606-1611.

3. Harris JD, Erickson BJ, Abrams GD, et al. Methodologic quality of knee articular cartilage studies. Arthroscopy 2013;29:1243-1252.e5. 
4. Montané E, Vallano A, Vidal X, Aguilera C, Laporte J-R. Reporting randomised clinical trials of analgesics after traumatic or orthopaedic surgery is inadequate: A systematic review. BMC Clin Pharmacol 2010;10:2.

5. Chan S, Bhandari M. The quality of reporting of orthopaedic randomized trials with use of a checklist for nonpharmacological therapies. J Bone Joint Surg Am 2007;89: 1970-1978.

6. Schulz KF, Altman DG, Moher D. CONSORT 2010 statement: Updated guidelines for reporting parallel group randomized trials. Ann Intern Med 201 1;154:291.

7. Chess LE, Gagnier J. Risk of bias of randomized controlled trials published in orthopaedic journals. BMC Med Res Methodol 2013;13:76.

8. Hoffmann TC, Glasziou PP, Boutron I, et al. Better reporting of interventions: Template for Intervention Description and Replication (TIDieR) checklist and guide. BMJ 2014;348:g 1687.

9. Murad MH, Wang Z. Guidelines for reporting metaepidemiological methodology research. Evid Based Med 2017;22:139-142.

10. Jellison S. TIDieR orthopedic surgery. https://doi.org/10. 17605/OSF.IO/EYH5F. Published 2019. Accessed July, 1, 2019.

11. Lai R, Chu R, Fraumeni M, Thabane L. Quality of randomized controlled trials reporting in the primary treatment of brain tumors. J Clin Oncol 2006;24:1 136-1144.

12. Thabane L, Chu R, Cuddy K, Douketis J. What is the quality of reporting in weight loss intervention studies? A systematic review of randomized controlled trials. Int $J$ Obes 2007;31:1554-1559.

13. Ghimire S, Kyung E, Kang W, Kim E. Assessment of adherence to the CONSORT Statement for quality of reports on randomized controlled trial abstracts from four high-impact general medical journals. Trials 2012;13:77.

14. Checketts JX, Sims MT, Detweiler B, Middlemist K, Jones J, Vassar M. An evaluation of reporting guidelines and clinical trial registry requirements among orthopaedic surgery journals. J Bone Joint Surg Am 2018;100:e15.

15. Samaan Z, Mbuagbaw L, Kosa D, et al. A systematic scoping review of adherence to reporting guidelines in health care literature. J Multidiscip Healthc 2013;6: 169-188.

16. Turner L, Shamseer L, Altman DG, et al. Consolidated standards of reporting trials (CONSORT) and the completeness of reporting of randomised controlled trials (RCTs) published in medical journals. Cochrane Database Syst Rev 2012;11:MR000030.

17. Hopewell S, Ravaud P, Baron G, Boutron I. Effect of editors' implementation of CONSORT guidelines on the reporting of abstracts in high impact medical journals: Interrupted time series analysis. BMJ 2012;344:e4178.

18. Linden A. Conducting interrupted time-series analysis for single- and multiple-group comparisons. Stata J 2015;15: 480-500.

19. Hanley JA. Statistical analysis of correlated data using generalized estimating equations: An orientation. Am J Epidemiol 2003;157:364-375.

20. Hughes BT. TIDieR data analysis. https://doi.org/https://doi. org/10.17605/OSF.IO/3A46J. Published 2019. Accessed July 25, 2019
21. Duff JM, Leather H, Walden EO, LaPlant KD, George TJ. Adequacy of published oncology randomized controlled trials to provide therapeutic details needed for clinical application. J Natl Cancer Inst 2010;102:702-705.

22. Hoffmann TC, Erueti C, Glasziou PP. Poor description of non-pharmacological interventions: Analysis of consecutive sample of randomised trials. BMJ 2013;347: f3755.

23. Glasziou P, Meats E, Heneghan C, Shepperd S. What is missing from descriptions of treatment in trials and reviews? BMJ 2008;336:1472-1474.

24. Schroter S, Glasziou P, Heneghan C. Quality of descriptions of treatments: A review of published randomised controlled trials. BMJ Open 2012;2:e001978.

25. Chantebel R, Chesneau A, Tavernier E, El-Hage W, Caille A. Completeness of descriptions of repetitive transcranial magnetic stimulation intervention: A systematic review of randomized controlled trials of rTMS in depression. J ECT 2019;35:7-13.

26. Yamato T, Maher C, Saragiotto B, et al. The TIDieR checklist will benefit the physiotherapy profession. Physiother Theory Pract 2017;33:267-268.

27. Jacquier I, Boutron I, Moher D, Roy C, Ravaud P. The reporting of randomized clinical trials using a surgical intervention is in need of immediate improvement: A systematic review. Ann Surg 2006;244:677-683.

28. Yamato TP, Maher CG, Saragiotto BT, Hoffmann TC, Moseley AM. How completely are physiotherapy interventions described in reports of randomised trials? Physiotherapy 2016;102:121-126.

29. Borrelli B, Sepinwall D, Ernst D, et al. A new tool to assess treatment fidelity and evaluation of treatment fidelity across 10 years of health behavior research. J Consult Clin Psychol 2005;73:852-860.

30. Moncher FJ, Prinz RJ. Treatment fidelity in outcome studies. Clin Psychol Rev 1991;11:247-266.

31. Borrelli B. The assessment, monitoring, and enhancement of treatment fidelity in public health clinical trials. J Public Health Dent 2011;71:S52-S63 (suppl 1).

32. Koh KH, Kang KC, Lim TK, Shon MS, Yoo JC. Prospective randomized clinical trial of single- versus double-row suture anchor repair in $2-$ to $4-\mathrm{cm}$ rotator cuff tears: Clinical and magnetic resonance imaging results. Arthroscopy $2011 ; 27: 453-462$.

33. Hirst A, Altman DG. Are peer reviewers encouraged to use reporting guidelines? A survey of 116 health research journals. PLoS One 2012;7:e35621.

34. Moher D, Schulz KF, Altman D, CONSORT Group. The CONSORT Statement: Revised recommendations for improving the quality of reports of parallel-group randomized trials 2001. Explore 2005;1:40-45.

35. Turner L, Shamseer L, Altman DG, Schulz KF, Moher D. Does use of the CONSORT Statement impact the completeness of reporting of randomised controlled trials published in medical journals? A Cochrane review. Syst Rev 2012;1:60.

36. Journal of Orthopaedic \& Sports Physical Therapy. Author center, https://www.jospt.org/page/authors. Accessed October 1, 2019.

37. International Committee of Medical Journal Editors. Recommendations. Preparing for submission, http://www.icmje. 
org/recommendations/browse/manuscript-preparation/ preparing-for-submission.html. Accessed July 31, 2019.

38. National Library of Medicine, National Institutes of Health, https://www.nlm.nih.gov/. Published October 1993. Accessed August 28, 2019.

39. Chan L, Heinemann AW, Roberts J. Elevating the quality of disability and rehabilitation research: Mandatory use of the reporting guidelines. Ann Phys Rehabil Med 2014;57: 558-560.

40. Barnes C, Boutron I, Giraudeau B, Porcher R, Altman DG, Ravaud P. Impact of an online writing aid tool for writing a randomized trial report: The COBWEB (CONSORTbased WEB tool) randomized controlled trial. BMC Med 2015;13:221. 